\title{
The Review of Transnational Higher Education
}

\author{
Zhang Zhenzhen ${ }^{1, *}$, Gu Juan ${ }^{2}$ \\ ${ }^{1}$ Jiangsu Vocational College of Medicine, Yancheng, Jiangsu province, China \\ 2 Jiangsu Vocational College of Medicine, Yancheng, Jiangsu province, China
}

Keywords: Transnational higher education; Education and teaching activities; Cross-border education

\begin{abstract}
In the past three decades, China becomes an increasingly popular market for International Higher Education and Transnational Higher Education (TNHE). Because the TNHE always involve a pair of institutions from two countries, the definition and regulation of other countries significantly influenced the TNHE programs in China. As distinct from education and training provided in a purely distance mode, transnational education and training includes a physical presence of instructors offshore, either directly by the Australian provider, or indirectly through a formal agreement with a local institution/organization. However, in mainland China, most of the TNHE programs adopted neither mode above for the authorize of China's reinforced that the TNHE programs held in China must be aligned and paired with a local HEI, which almost eliminated the possibility of establishing an international branch campus independently by a foreign HEI alone.
\end{abstract}

\section{Introduction}

In the past three decades, China becomes an increasingly popular market for International Higher Education and Transnational Higher Education (TNHE) (Huang, 2003; Altbach, 2007; Naidoo, 2009; and Mok and Yu, 2011). Comparing to International Education, TNE usually refers to a project which offers the education provision from one country in another (British Council, 2013). For now, the phenomenon shows no signs of any kind of slowing down, from the national data to individual Transnational Education Institutions (TNHEIs) (Huang, 2007; Shams, and Huisman, 2011; British Council, 2013; Ministry of Education, 2014). By the time of 29th June, 2015, 855 undergraduate TNHE projects has been approved and being operated by China Mainland based TNHEIs in 25 provinces (Ministry of Education, 2014).

From the perspective British Council and Chinese higher education providers on TNHE, the term of TNE refers to joint operation of higher education programs or institutions with partners from foreign countries (Huang, 2007; British Council, 2006, British Council, 2013; Bui, and Nguyen, 2014). In term of joint, collaborative, cooperation, or any other norm which might be referred to the similar project or program, it refers the aspect of the operations, management, and the strategy of the host organizations (Shams and Huisman, 2011). Through a number of types of TNHE module that the pair of institutions had chosen, it reflects the strategies which they would like to adopt in the operations in order to benefit the short-term and long-term goals.

\section{The influence of the different definition of transnational higher education}

Because the TNHE always involve a pair of institutions from two countries, the definition and regulation of other countries significantly influenced the TNHE programs in China. The China Ministry of Education (1995) defined TNE as 'Those foreign corporate, individuals, and related international organizations in cooperation with educational institutions or other social organizations with corporate status in China, jointly establish education institutions in China, recruit Chinese citizens as major educational objectives, and undertake education and teaching activities.' In Australia, the definition is 'Australian transnational education and training, also known as offshore or cross-border education and training, refers to the delivery and/or assessment of programs/courses 
by an accredited Australian provider in a country other than Australia, where delivery includes a face-to-face component...

As distinct from education and training provided in a purely distance mode, transnational education and training includes a physical presence of instructors offshore, either directly by the Australian provider, or indirectly through a formal agreement with a local institution/organization.' (Australian Department of Education and Science, 2005). TNHE will also be defined as cross-border education as $s$ 'the movement of people, knowledge, programs, providers, ideas, curricula, projects, research and services across national or regional jurisdictional borders. Cross-border education is a subset of internationalization and can be part of development cooperation projects, academic exchange programs and commercial initiatives. Cross-border is a term that is often used interchangeably with other terms such as transnational, offshore, and borderless education. While there are some conceptual differences among these terms, they usually refer to similar types of activities: franchise, branch campus, virtual universities and double/joint degree' (Knight, 2007). New Zealand considered the delivery of formal education qualification of New Zealand in other countries as the TNHE, which is uniquely simple comparing to other countries (Education New Zealand Trust, 2007). DAAD of Germany emphasizes the issue of academic responsibility in its definition of transnational education, where the German TNE projects operates, the standards for curricula and quality must be set up by the German providers (DAAD, 2012).

\section{The reasons for the development of TNHE in china}

In turn, the definition influences the mode of TNHE in China where the education is delivered to the Chinese students. There are several modes that TNHE will be held and delivered in China for a number of reasons:

1 Lack of data. Very few host countries collect data on TNE programs on offer to their tertiary students. Without such data, it's difficult to understand exactly how the programs are being delivered.

2 Terminology differences. Different countries and institutions have a different perspective, depending on whether they are senders or hosts of TNE programs. This means they often use different terms to describe the same activity. For example, what's referred to as a 'franchise' arrangement by a sending HEI may be referred to as a 'top-up' arrangement by the host HEI.

3 Use of generic terms. In both sending and host countries, one TNE delivery mode may be used generically to refer to all modes of delivery. For example, twinning, collaborative programs and joint degrees.

4 Overlapping and evolutionary nature of TNE delivery modes. The various TNE delivery modes are not mutually exclusive. An individual arrangement may involve elements of two or more delivery modes. Also, the increasing role of ICT has provided for increasingly innovative ways for HEIs to collaborate. (British Council, 2013: pp14).

\section{The differences of three modes of TNHE in china}

The difference and difficulties that the TNHE providers confronted with correspondingly generates a vast of number of modes in TNHE delivery. Accordingly, the factors leads to several modes of TNHE delivery in China, which at least could be summarized as British Council researched in 7 modes (British Council 2013). Huang (2008) stated at least 3 modes of TNHE in China and Hong Kong which was the mainstream of the delivery.

Speaking of the modes of TNHE, each approaches reflects the strategy of both HEIs while the strategy and operations management in the TNHE program is subjected to be changed correspondingly.

International Branch campus is one of the mode that the sending Higher Education Institutions (HEIs) dominates the TNHE operations in its overseas Campus (Shams, and Huisman, 2011; and Becher, 2015). The stand-alone satellite campus in the host country is responsible to its own management, 
including recruiting, admission, and program delivery and awarding (British Council, 2013). It is one of the typical mode of TNHE that, for the nature of the TNHE, there are two HEIs involved in a TNHE program, one as the sending HEI, and host HEI as the other, it will become complicated when the program is subjected to both HEIs under dual regulations of both of the countries. Considering the definition and regulations of TNHE in the countries (Ministry of Education, 2015; British Council, 2006, and British Council, 2013), hosted in a China's HEI and sent by a UK HEI for instance, required by the authorities of either side, it is hardly actually operation an overseas campus independently. Quality assurance of the program, which is the responsibility of both the sending HEI and the host HEI, in compliance of China's regulation and the UK's regulation for instance.

Validation Programs, which is the opposite of the International Branch Campus mode, requires very little intervention of the sending HEI, for it validates the delivery in the host HEI only and issue the qualification or credits to the students who were educated by the host HEI (British Council, 2006, British Council, 2013; and DAAD, 2012). This mode requests hosting HEI to fully plan and operate the program while the sending HEI is not much more than an accreditation body.

However, in mainland China, most of the TNHE programs adopted neither mode above for the authorize of China's reinforced that the TNHE programs held in China must be aligned and paired with a local HEI, which almost eliminated the possibility of establishing an international branch campus independently by a foreign HEI alone(Ministry of Education, 1996, and 2015). Also, further requirements and policies in a large proportion of provinces in China restated that the curriculum and staffing of a TNHE program in China must consist of $1 / 3$ or more provided by the sending HEI, where a full report and arrangement should be assured since the application documentations have been drafting. Therefore, the TNHE programs in China is usually witnessed as a mode of Twinning Program, Dual Degree, or Joint Degree.

\section{Conclusion}

International Higher Education and Transnational Higher Education (TNHE) has become increasingly popular globally, including mainland China, for a number of reasons that in both the market and suppliers believe the mutual benefit could be achieved. Because the TNHE always involve a pair of institutions from two countries, the definition and regulation of other countries significantly influenced the TNHE programs in China. As distinct from education and training provided in a purely distance mode, transnational education and training includes a physical presence of instructors offshore, either directly by the Australian provider, or indirectly through a formal agreement with a local institution/organization. However, in mainland China, most of the TNHE programs adopted neither mode above for the authorize of China's reinforced that the TNHE programs held in China must be aligned and paired with a local HEI, which almost eliminated the possibility of establishing an international branch campus independently by a foreign HEI alone.

\section{References}

[1] Huang, F. (2003). Transnational higher education: A perspective from China. Higher Education Research and Development, 22(2), 193-203.

[2] Altbach, P. G. (2007). Peripheries and Centers: Research Universities in Developing Countries. Higher Education Management and Policy, 19(2), 1-24.

[3] Naidoo, V. (2009). Transnational Higher Education A Stock Take of Current Activity. Journal of studies in international education, 13(3), 310-330.

[4] Mok, K. H., \& Yu, K. M. (2011). The quest for regional education hub status and transnational higher education: Challenges for managing human capital in Asia. Asia Pacific Journal of Education, 31(3), 229-248. 
[5] British Council (2013). The shape of things to come: The evolution of transnational education: data, definitions, opportunities and impacts analysis.

[6] Huang, F. (2007). Internationalization of Higher Education in the Developing and Emerging Countries: A Focus on Transnational Higher Education in Asia. Journal of studies in international education.

[7] Shams, F., \& Huisman, J. (2011). Managing offshore branch campuses: An analytical framework for institutional strategies. Journal of Studies in International Education, 1028315311413470.

[8] Knight, J. (2007). Cross-border higher education: Issues and implications for quality assurance and accreditation.

[9] Department for Business, Innovation and Skills (2014). The Value of Transnational Education to the UK.

Becker, R. (2015). International branch campuses: New trends and directions. International Higher Education (58).

[10] Chambers, E. (2003). Cultural Imperialism or Pluralism: Cross-Cultural Electronic Teaching in the Humanities. Arts and humanities in higher education, 2(3), 249-264.

[11] Child, J., \& Tsai, T. (2005). The Dynamic between Firms’ Environmental Strategies and Institutional Constraints in Emerging Economies: Evidence from China and Taiwan. Journal of Management Studies, 42(1), 95-125.

[12] De Wit, B., \& Meyer, R. (2004). Strategy: process, content, context; an international perspective (3rd Ed.). London: Thomson learning.

[13] Debowski, S. (2008). Risky business: Effective planning and management of transnational teaching. In L. Dunn \& M. Wallace (Eds.), Teaching in transnational higher education: enhancing learning for offshore international students (1st ed., pp. 204-215). New York: Routledge.

[14] Evans, S., \& Morrison, B. (2011). Meeting the challenges of English-medium higher education: The first-year experience in Hong Kong. English for Specific Purposes, 30(3), 198-208.

[15] Green, M. F., Marmolejo, F., \& Egron-Polak, E. (2012). The internationalization of higher education. The SAGE handbook of international higher education, 439.

[16] Garrett, R. (2004). Transnational delivery by UK higher education, part1: innovation and competitive advantage. London: The Observatory on Borderless Higher Education.

[17] Healey, N., \& Michael, L. (2014). Towards a New Framework for Analyzing Transnational Education. Higher Education Policy.

[18] Lien, D. (2008). Economic analysis of transnational education. Education Economics, 16(2), 149-167.

[19] British Council (2013). The shape of things to come: The evolution of transnational education: data, definitions, opportunities and impacts analysis 